\title{
Thoughts and Practice of the Construction of Master's Programs in Provincial Universities in the New Era
}

\author{
Wentao Sui ${ }^{*}$, Huirong Zhang, Lin Yuan, Yajun Jin \\ Shandong University of Technology, \\ No.266 Xincun West Road, Zhangdian District, Zibo City, Shandong Province,China \\ ${ }^{*}$ Corresponding authors 's email: suiwt [AT] 163.com
}

\begin{abstract}
Aiming at the shortcomings of talent training characteristics and practical ability improvement in the construction of master's degree programs in provincial universities in the new era, a solution was proposed to build a new engineering tutor construction team, develop a high-level talent introduction mechanism, and cultivate high-level scientific research results. Through a series of policies and measures to improve the ability to convert new and old kinetic energy services and the quality of social services.
\end{abstract}

Keywords - training characteristics, practical ability, high-level talent introduction, convert new and old kinetic energy

\section{INTRODUCTION}

The 2019 National Graduate Enrollment Survey Report states that Peking University received a total of 2,174 recommended master-exempt students in 2019, of which 2061 undergraduates came from "double first-class" universities, accounting for $94.8 \%$. Sun Yat-sen University received a total of 1945 recommended exempted master students in 2019, of which 1,770 undergraduates came from "double first-class" universities, accounting for $91 \%$. On the one hand, the number of students applying for postgraduate examinations across the country has reached a record high, and the number of graduate students recommended for "double first-class" universities has increased. It is required that the master's degree programs of provincial universities and colleges improve the content of development and improve the quality of discipline construction.

In order to adapt to the national innovation-driven development strategy and serve the conversion of old and new kinetic energy, universities should take the initiative to take an active part and actively participate in the transformation of old and new kinetic energy with high-quality development of education, providing them with strong talent and intellectual support. ${ }^{[1],[2]}$ Focus on serving the major projects of new and old kinetic energy conversion in Shandong Province, and cultivate high-quality application-oriented talents that meet the "four new" requirements of new and old kinetic energy conversion ${ }^{[3]}$ Promote the classified management of higher education, improve the modern vocational education system, and improve the ability to cultivate applied talents. ${ }^{[4]}$

\section{CURRENT STATUS OF THIS MAJOR}

Shandong University of Technology corresponding undergraduate specialty "Measurement and Control Technology and Instrumentation" was approved by the Ministry of Education in 2000 and undergraduate enrollment in 2001; the second-level master's degree "Testing Measurement Technology and Instrumentation (080402)" began in 2004 Enrollment; The discipline of "Instrument Science and Technology (0804)" was approved by the Ministry of Education as the first-level discipline master's degree authorization point in 2011, and in 2012, the first-level discipline "Instrument Science and Technology" began to recruit graduate students. The professional master's degree authorized in the field of instrumentation engineering was approved by the Ministry of Education in 2010, and enrollment began in 2011. Since the establishment of the corresponding undergraduate major in this discipline, it has been one of the majors of the school. In the 2011 data acquisition and professional evaluation of colleges and universities in Shandong Province, the Shandong University of Technology's measurement and control technology and instrumentation major has won the second place in Shandong Province's instrumentation professional evaluation for four consecutive years. In 2012, this major was rated as a specialty of Shandong Province. In 2013, it was identified as a radiation major in the construction of famous universities in Shandong Province. 


\section{THEORY AND PRACTICE OF CONSTRUCTION IDEAS}

\subsection{Theoretical method of constructing ideas}

Guiding by Xi Jinping's thought of socialism with Chinese characteristics in the new era, comprehensively implement the party's educational policy, adhere to the direction of running socialist schools, and take the Lider tree as the primary task for the construction of graduate tutors. The full implementation of graduate tutors is the first person responsible for graduate education. Requirements, adhere to the unity of teaching and educating people, and strive to build a team of high-quality graduate tutors with noble morality, rigorous academics, and guidance. Through a team of high-level postgraduate tutors, efforts are made to train a group of high-quality postgraduate talents who meet the requirements of the "new and new" of new and old kinetic energy conversion.

Relying on the advantages of disciplines and platforms of Shandong University of Technology, it has introduced and cultivated a high-level academic team with an advanced international and domestic first-class level in a reasonable age structure and outstanding innovation ability. Focusing on the national and local economic construction of Shandong Province, with the goal of serving major projects in the conversion of old and new kinetic energy in Shandong Province, through the integration of resources in schools, schools, and enterprises, we provide strong intellectual support for solving major scientific and technological problems in the mechanical engineering field of our province and even the country .

\subsection{Practical method of constructing ideas}

\subsubsection{Create a new engineering mentor team}

Facing the construction of new engineering disciplines, the mentor team needs to continue to explore in curriculum reform and discipline construction, revise graduate training programs, update the engineering talent knowledge system, and set up courses such as artificial intelligence, intelligent manufacturing, robotics, and cloud computing. In terms of teaching content, more attention is paid to leading-edge leadership and interdisciplinary cross-cutting. The latest developments in industry and technology, the latest requirements for talent training in the industry, and the latest achievements of teachers' scientific research are introduced into the teaching process.

\section{2 .2 Develop a flexible high-level talent introduction and use mechanism}

Make full use of various talent policy bonuses, build high-end talent teams around key discipline directions and key research areas, and achieve breakthroughs and increase in the introduction of high-level talents at the provincial level and above. With the chief expert and specially-appointed professors as the core, relying on the discipline, scientific research, and teaching platforms, the provincial and municipal talent projects are docked to form a group of talented teams that are competitive in the mainstream research direction, and more teams are selected for provincial and national team projects.

\section{2 .3 Enhance the capacity of young mentors}

The backbone teachers with experience cooperate actively with young teachers to help them develop rapidly. Actively create conditions for young teachers, give them more opportunities to participate in academic conferences at home and abroad, encourage young teachers to go abroad for training or academic exchanges, and improve the academic literacy and teaching and research level of young teachers in exchanges with first-class teaching institutions abroad, and continue to Learn and progress.

\section{2 .4 Construction of assessment and assessment mechanism for graduate tutors}

Establish a set of dynamic evaluation and assessment mechanism for the entire process of mentoring graduate students, implement certain research and teaching rewards for outstanding mentors, openly criticize irresponsible mentors, secondly focus on the quantification and evaluation of mentor academic levels and academic achievements, and The assessment of the excellent results guided by the students promotes the common progress of the tutor and the students from the side.

\section{2 .5 Actively develop a new model of school-enterprise cooperation}

Actively build enterprise innovation and entrepreneurship bases, enterprise technology transfer centers, and schoolenterprise joint engineering technology research centers, develop major projects for school-enterprise cooperation, important scientific and technological rewards, and the number of important technological achievements, and transform the latest scientific research achievements into the development of productivity and product progress. 


\section{PHASED PLANNING AND GOALS}

In the new era, the construction of provincial master's degree programs should focus on the "two hundred-year struggle goals", commit to serving the transformation of old and new kinetic energy, and achieve high-quality economic development as a guide. Following innovation is the first driving force for development. Innovation ${ }^{[5]}$, crossover and integration, coordination and sharing promote the construction of new engineering disciplines. Attach importance to learning and teaching, and rebuild the knowledge system of talents; reshape the quality concept of talent cultivation, innovate teaching methods and technologies, strengthen practical innovation and entrepreneurship, improve the cultivation model of innovative entrepreneurship talents, and strengthen technology transfer and achievement transformation. ${ }^{[6]}$

\subsection{Introduce high-level mentors}

$>$ Full-time introduction of mentors with the title of provincial talents (such as Shandong Province "Taishan Scholars" series of talents / Shandong young and middle-aged experts with outstanding contributions) 1-2 people.

$>$ Flexible introduction of national "double first-class" doctoral tutors.

Introduce more than 6 young doctors from home and abroad.

\subsection{Strengthen discipline construction}

$>$ Approve 2 national research projects, 5 provincial and ministerial research projects.

$>$ Publish more than 50 papers in core journals, of which more than 20 are included in SCI and EI.

$>$ Issue more than 10 invention patents and undertook 5-10 corporate projects.

\subsection{Cultivate new engineering talents}

$>$ Train 20 postgraduates.

> Newly add 2 or more postgraduate workstations, more than 2 off-campus practice bases, and more than 2 new parttime tutors.

\subsection{Enhancing the Academic Ability of Young Teachers}

$>$ Send more than one young and middle-aged backbone teacher to visit famous overseas universities.

$>$ Publish more than 5 high-level scientific research papers with overseas high-level experts .

$>$ Participate in teaching and research conferences of not less than 50 people.

The implementation scope of this project is the two degree points of Instrument Science and Technology (Master of Science) and Instrument Engineering (Master of Engineering) under the Instrument Department of the team. The project research will drive the teaching reform and practice of other related majors in the School of Mechanical Engineering, and the number of graduate students who will benefit will be about 200 .

\section{POLICY GUARANTEE}

\subsection{Funding support for conversion of old and new kinetic energy}

In 2018, the team's department was approved for the construction project of the Shandong Province New and Old Kinetic Energy Conversion Specialty Docking Industry Professional Group. According to the project construction goals and requirements, 2018 to 2022 is the implementation period of the professional docking industry project, and 2018 to 2020 is the financial capital investment In the future, the provincial finance will set up project funds in accordance with the standard of 12 million yuan per year per project to support schools to promote professional discipline construction and talent training, which will provide more powerful talent guarantees for the province's "top ten" industry development and conversion of old and new kinetic energy. And technical support.

\subsection{Funding for New Engineering}

On April 17, 2018, Xinhua Medical signed a school-enterprise strategic cooperation agreement with Shandong University of Science and Technology, invested 200,000 yuan, planned to establish a postdoctoral innovation practice base, established a "Xinhua health industry dual innovation platform", deepened new product research and development cooperation, and explored Carry out in-depth strategic cooperation in areas such as the school-enterprise collaborative training mechanism. The establishment and operation of the new engineering experimental class in the direction of "smart medical instruments" is a new model for collaborative training of school-enterprise talents. 


\section{CONCLUSION}

Aiming at the thinking and practice of the construction of master's degree programs in provincial universities in the new era, this paper proposes a series of theoretical and practical measures, and makes a certain outlook on the training goals. In order to serve the conversion of new and old kinetic energy, it will cultivate "four-possible" graduate talent And work hard to promote high-quality economic development.

\section{ACKNOWLEDGEMENT}

This project was supported by Research project of graduate education and teaching reform in Shandong Province (Project No.: SDYJG19105)

\section{REFERENCES}

[1] Qu Pingbo,"Research on the Cultivation Mechanism of Innovative Talents under the Background of New and Old Kinetic Energy Conversion" New Business Weekly,pp.194, 2019, (5)

[2] Yu Zhongjun,Kong Lingjuan," Study on the Talent Cultivation Model of the Integration of New, Old and Kinetic Energy in the Production, Learning and Research Integration", China Business \& Trade,pp.254-256, 2019, (6)

[3] Hao Nini,Yang Junru,"Analysis of Effective Ways to Transform New and Old Kinetic Energy in Higher Education Services", The Guide of Science \& Education,pp.15-16,2019,(26)

[4] Shi Meng,Zhang Tiqin,"Cultivation of high-quality applied talents in private colleges and universities under the background of new and old kinetic energy conversion",Journal of Zhejiang Shuren University,pp.17-23,2019,19,(6)

[5] Xu Aiping,Zhou Weibin," Accelerate the induction of high-end innovative talents and promote the high-quality development of Tianjin's economy", City,pp. 21-27, 2019, (9)

[6] Zhong Denghua,"Connotation and Action of New Engineering Course Construction", Research in Higher Education of Engineering,pp.1-6,2017,(3) 